\title{
Candida: an unexpected cause of the acute abdomen
}

\author{
Sri Ganeshamurthy Thrumurthy, ${ }^{1}$ Stephenie Tiew, ${ }^{2}$ Nicholas Wood, ${ }^{3}$ Arnab Bhowmick ${ }^{2}$ \\ ${ }^{1}$ Department of Surgery, Lancashire Teaching Hospitals NHS Foundation Trust, Preston, UK; \\ 2Department of Surgery, Royal Preston Hospital, Preston, UK; \\ ${ }^{3}$ Department of Gynaecology, Royal Preston Hospital, Preston, UK \\ Correspondence to Sri Ganeshamurthy Thrumurthy, srigan@doctors.org.uk
}

\section{SUMMARY}

The infected intrauterine contraceptive device (IUCD) is a well-described cause of the acute abdomen. However, severe pelvic infection from Candida is an extremely rare complication of the IUCD. We present the first reported description of a Candida-infected IUCD manifesting as an acute abdomen where the degree of infection precluded a conclusive diagnostic workup and necessitated multiple laparotomies. This case highlights the importance for the clinicians to thoroughly exclude such causes of acute sepsis even after exclusion in the presenting history.

\section{BACKGROUND}

Amongst the myriad complications of intrauterine contraceptive devices, the complication of pelvic infection with Candida albicans subsequently presenting as an acute abdomen has never previously been reported.

\section{CASE PRESENTATION}

A 51-year-old Caucasian woman was referred by her general practitioner to the surgical assessment unit with a 2-day history of worsening right loin pain associated with anorexia and severe urgency of defaecation. Past medical history included poorly controlled diabetes mellitus, smoking 10 packs/year and no recent sexual activity. Abdominal examination revealed generalised abdominal distension and a firm, tender, suprapubic mass. She was pyrexial $\left(38.4^{\circ} \mathrm{C}\right)$ with a respiratory rate of $25 / \mathrm{min}$, pulse of $114 /$ min and blood pressure of 154/94 $\mathrm{mm} \mathrm{Hg}$.

Urgent blood tests yielded leucocytosis $\left(25.4 \times 10^{9} / 1\right.$, normal $\left.4-11 \times 10^{9} / 1\right)$ and a raised $C$ reactive protein (471.7 $\mathrm{mg} / \mathrm{l}$, normal $0-5 \mathrm{mg} / \mathrm{l})$. Plain abdominal radiography was unremarkable. An abdominal and pelvic ultrasound was carried out, which revealed dilated intrahepatic and common bile ducts and bilateral hydronephroses. An intrauterine contraceptive device (IUCD) was seen in the cervical region and a cystic mass with prominent septae (figure 1) was seen adjacent to the bladder raising the possibility of an ovarian cyst. Within this time, two separate sets of blood cultures (ie, a second set obtained due to repeated spikes in temperature), including urine and stool cultures, revealed no infectious organisms whatsoever.

A CT scan of the abdomen was requested and this revealed a large pelvic abscess $(14.5 \mathrm{~cm} \times 8.5 \mathrm{~cm}$, figure 2) containing a small focal density. The radiological diagnosis was that of an appendicular abscess with a small appendicolith. Bilateral cystic dilatations related to the adnexa suggested secondary hydrosalpinges. The IUCD was confirmed to be lying within the cervix (figure 3). The patient was started on intravenous fluids and antibiotics (cefuroxime and metronidazole). In view of the clinical and radiological findings, a laparotomy was performed and the pelvic abscess was drained. The cause of the abscess was not easily identifiable so a thorough lavage was undertaken. Two drains were placed into the pelvis and the abdomen was closed.

Three days later, the patient again deteriorated, showing signs of severe sepsis (temperature $38.5^{\circ} \mathrm{C}$, pulse 123 / min, blood pressure $117 / 67 \mathrm{~mm} \mathrm{Hg}$ and respiratory rate $30 / \mathrm{min}$ ). Another set of blood cultures was obtained but, as with previous sets, this also eventually revealed no infectious organisms. A subsequent CT scan demonstrated a recurrent right adnexal collection and a left-sided pelvic collection tracking up anteriorly to the left psoas muscle. The decision was made for a 'relook' laparotomy and a gynaecological opinion was requested intraoperatively. A salpingectomy was performed for a right pyosalpinx; the appendix was also removed followed by a pelvic lavage. It was at this juncture that a discussion occurred about the IUCD being the likely cause of pelvic infection. The IUCD threads were visible at the cervix and the copper device was easily removed. After 2 days in intensive care, the patient was transferred to the ward.

Microbiological analysis of pus samples from the pelvis and the IUCD was positive for Candida albicans. It was suggested that the tubo-ovarian abscess and subsequent pelvic infection were consequences of the Candidainfected IUCD. The patient later described having the IUCD inserted over 10 years prior to this without having the IUCD checked or changed since then.

\section{OUTCOME AND FOLLOW-UP}

Our patient underwent a relatively prolonged inpatient recovery but was well when reviewed 2 months postdischarge.

\section{DISCUSSION}

Loin pain in the acute abdomen is commonly urological in origin (eg, pyelonephritis). In females, differential diagnoses include gynaecological (eg, ectopic pregnancy, ruptured ovarian cyst, endometriosis, pelvic inflammatory disease (PID)) and gastrointestinal (eg, appendicitis, bowel abscess) pathologies. 


\section{BMJ Case Reports}

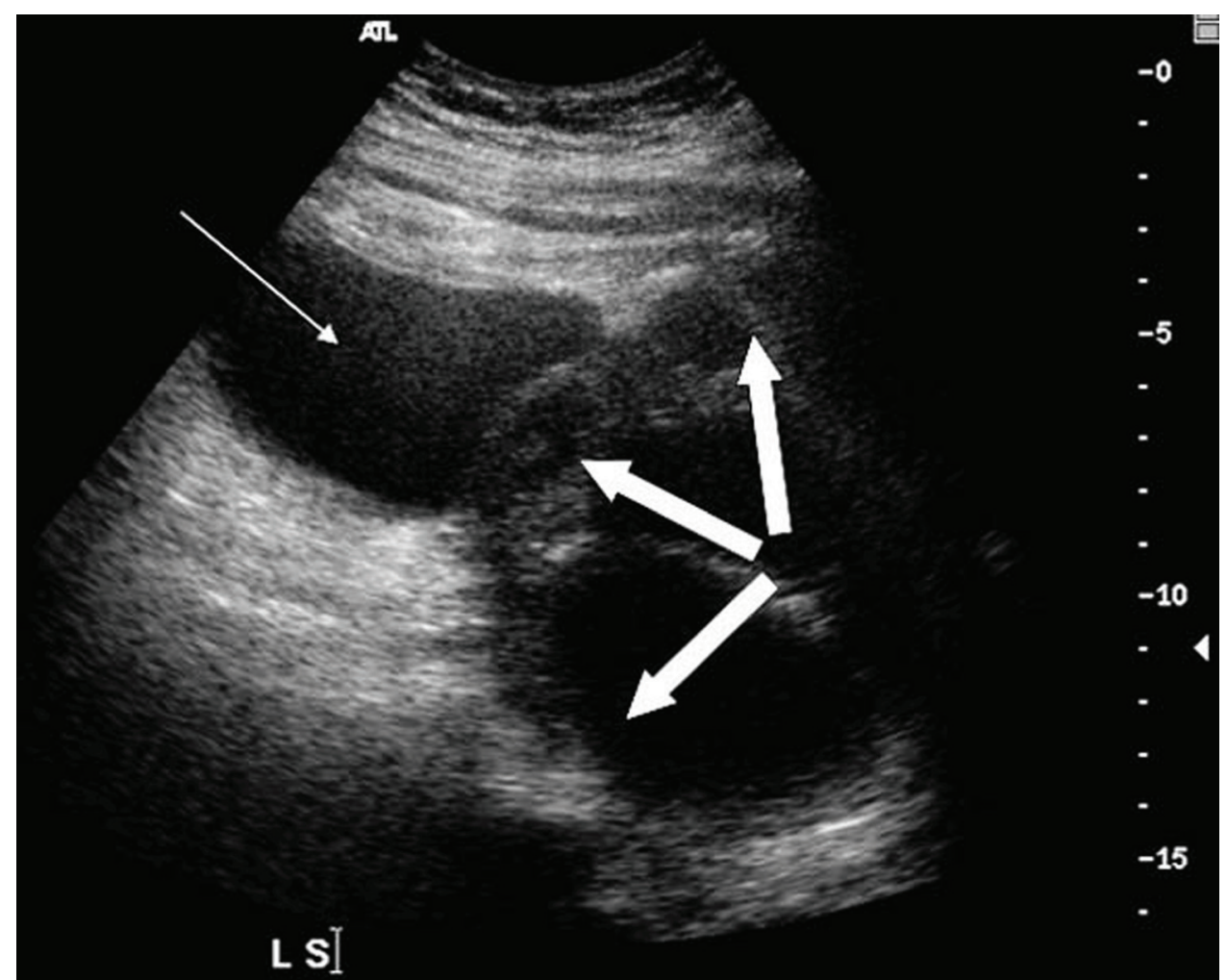

Figure 1 Pelvic ultrasound scan demonstrating a hypoechogenic region with visible septae (thick arrows) and the adjacent bladder (thin arrow).

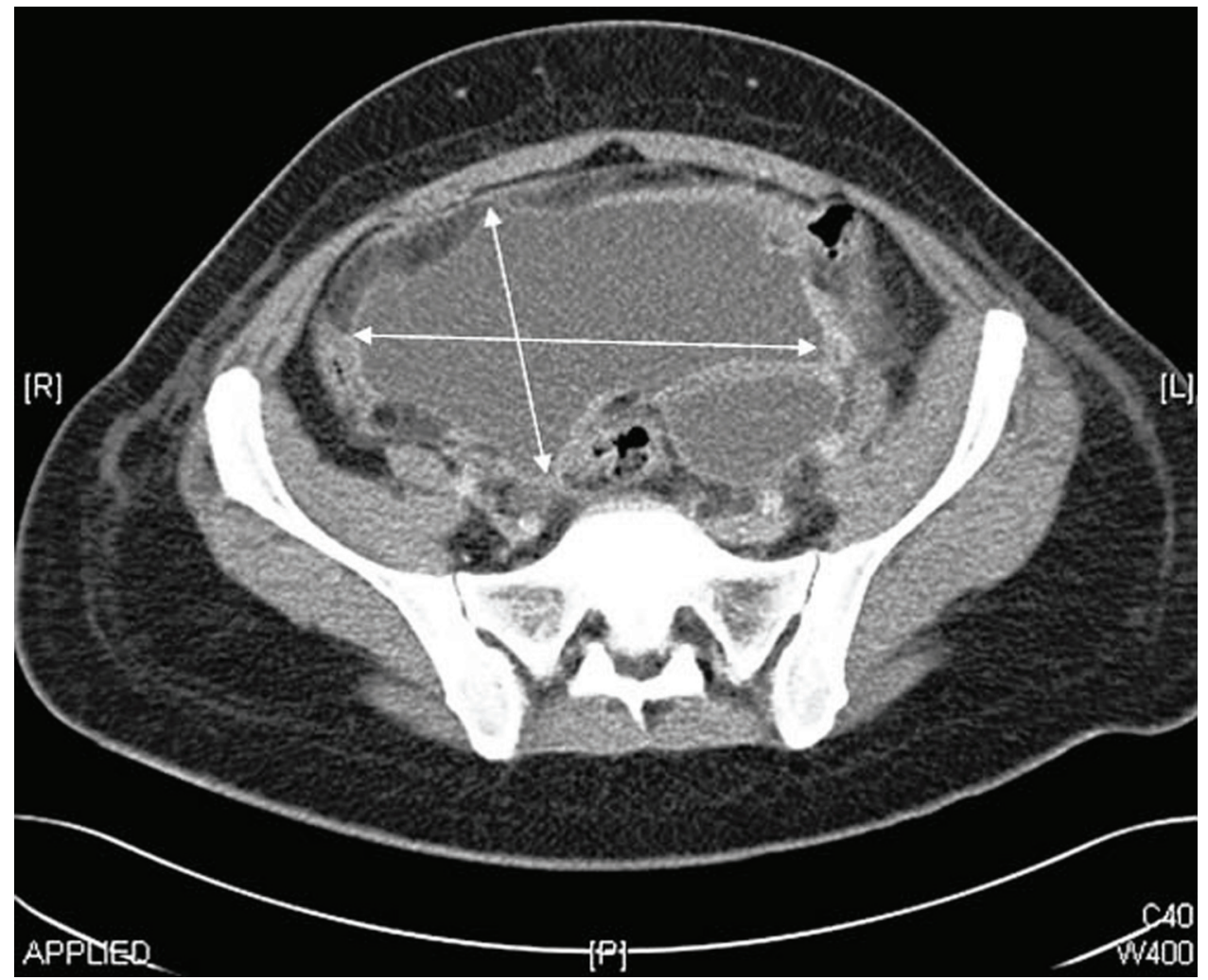

Figure 2 Pelvic CT scan demonstrating a $14.5 \times 8.5 \mathrm{~cm}$ abscess (arrows) within the pelvic cavity. 


\section{BMJ Case Reports}

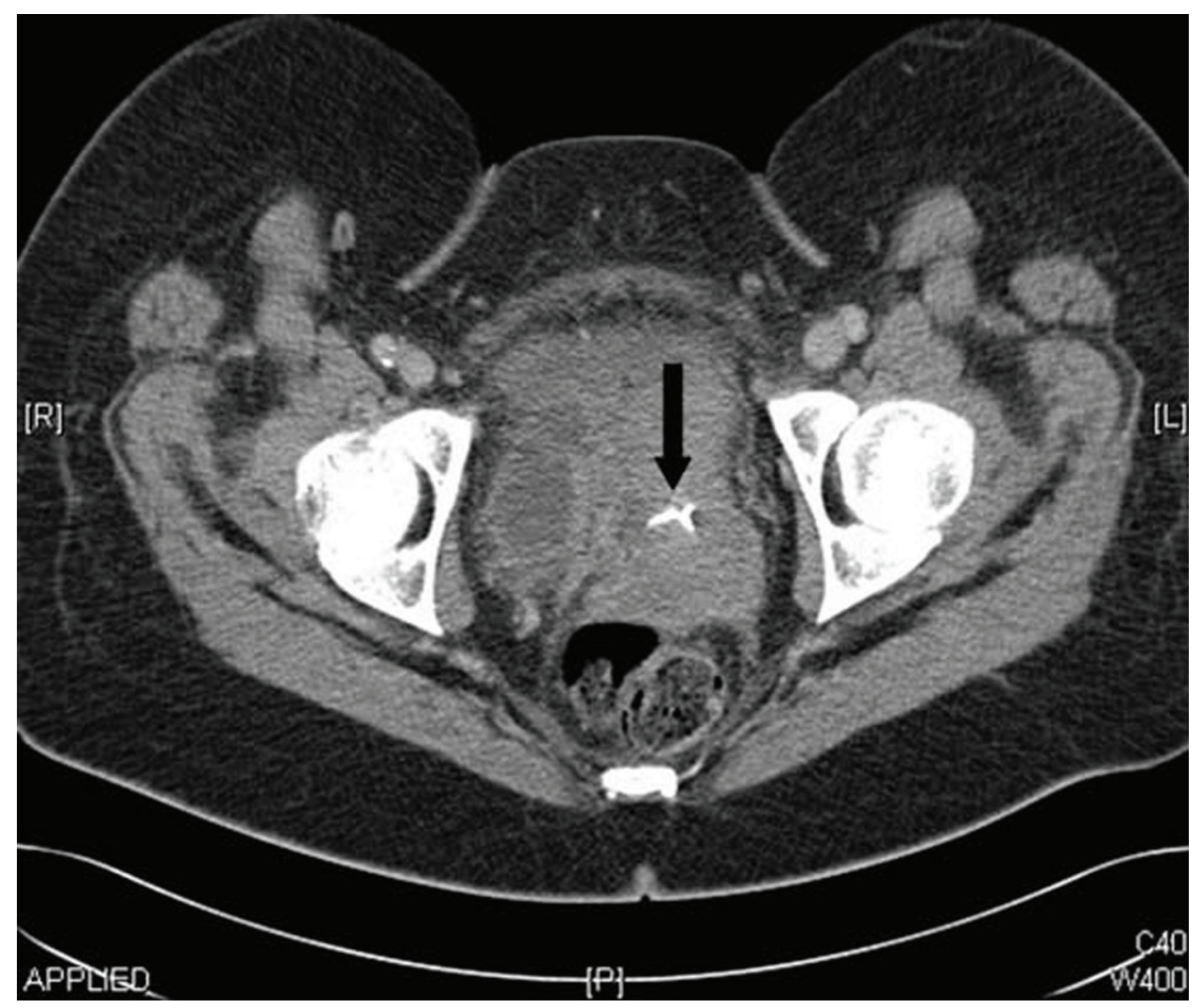

Figure 3 Pelvic CT scan confirming the presence of the intrauterine contraceptive device within the cervix (arrow).

The loin pain in our patient was attributed to tubo-ovarian abscess but the cause of this could not be identified at the first laparotomy-the sheer amount of pus in the abdomen had precluded adequate identification of pelvic anatomy. Despite medical treatment and surgical drainage, worsening sepsis ensued. The second CT scan localised the displaced IUCD previously suggested on ultrasound. The second laparotomy saw far better anatomical definition following the abscess drainage; the IUCD was then removed and the patient subsequently improved. It should be noted that over the course of treatment, no antifungal drugs were prescribed empirically (ie, before confirmation of IUCD contamination) because of the rarity of Candida in such presentations (see below). In addition, the local microbiologist on many occasions advised against the administration of antifungal treatment even after IUCD removal because not only had the source of infection been removed, but all previous blood cultures had been negative.

In this case, the displaced IUCD was believed to be the source of the pelvic abscess. A literature search of Medline, Embase and NHS Evidence revealed rare descriptions of septic complications of uterine coils. Prolonged retention of an IUCD ( $>8$ years) may lead to salpingitis and tubo-ovarian abscess. ${ }^{1}$ There is a small increase in the risk of pelvic infection in the first 20 days after insertion of an IUCD. Thereafter, the risk is the same as in the non-IUCD using population during licensed use. In the UK, the greatest duration of licensed IUCD use is 8 years. However, it is accepted UK practice to recommend that a copper IUCD inserted at age
40 years or over may be retained beyond the licensed duration until contraception is no longer required. ${ }^{2}$ The overall rate of PID among 22908 IUCD insertions and during 51399 woman-years of follow-up was 1.6 cases per 1000 woman-years of use. ${ }^{3}$ A retrospective study of 62 cases of pelvic abscesses showed that $36 \%$ underwent either laparotomy or laparoscopy. ${ }^{4}$

Despite the above, the authors acknowledge that sheer contamination of an IUCD does not necessarily implicate it as an infectious focus of sepsis or imply that the contamination is the source of any subsequent ascending infection. It is increasingly acknowledged that PID may be caused by fastidious, hard-to-culture, organisms (eg, certain anaerobes). ${ }^{5}$ Whether or not empirical antifungal treatment would be beneficial in such situations is unclear but it is imperative that expert microbiological advice is sought in all of such circumstances.

Actinomyces israeli is the commonest organism associated with IUCD-related pelvic abscesses and septic complications. While IUCD-related actinomycosis is well-documented in the literature, only two cases of Candida-related tubo-ovarian abscess from IUCDs have been published to date. ${ }^{67}$ Our patient had several risk factors for candidiasis, including her age, poorly controlled diabetes mellitus and smoking. However, it may be worth considering the possibility that although only Candida was cultured from our patient's IUCD, the intravenous antibiotics administered may have suppressed any Actinomyces or other co-existing organisms. Nonetheless, Candida should be considered a cause in any case where tubo-ovarian abscess remains unresponsive to conventional antibiotic treatment particularly 


\section{BMJ Case Reports}

in patients with risk factors for Candida infection and who have an IUCD in situ. ${ }^{4}$

In the UK, approximately $5 \%$ of all sexually active women use IUCDs. ${ }^{8}$ Current standards of follow-up care have significantly reduced the incidence of associated PID and pelvic abscess in long-term IUCD users. Nevertheless, we recommend that the presence of an IUCD be thoroughly excluded in all cases with a working diagnosis of pelvic abscess based on clinical or ultrasonographic evaluation. Within the realm of general surgery, it is imperative that a focused gynaecological history be obtained in all cases of acute abdomen in females: particularly, the type and duration of contraception should be ascertained, regardless of age.

In summary, intrauterine devices should always be considered as a potential source of infection in gross PID. The authors also emphasise the need for IUCD users and primary care practitioners to be aware of the role of regular 'coil checks' in avoiding such rare but potentially lifethreatening complications.

\section{REFERENCES}

1 Charonis G, Larsson PG. Prolonged use of intrauterine contraceptive device as a risk factor for tubo-ovarian abscess. Acta Obstet Gynecol Scand 2009;88:680-4.

2 Penney G, Brechin S, de Souza A, et al. FFPRHC Guidance (January 2004). The copper intrauterine device as long-term contraception. J Fam Plann Reprod Health Care 2004;30:29-41; quiz 42.

3 Farley TM, Rosenberg MJ, Rowe PJ, et al. Intrauterine devices and pelvic inflammatory disease: an international perspective. Lancet 1992;339:785-8.

4 Tanir HM, Hassa H, Ozalp S, et al. Pelvic abscess in intrauterine device users. Eur J Contracept Reprod Health Care 2005;10:15-18.

5 Trigg BG, Kerndt PR, Aynalem G. Sexually transmitted infections and pelvic inflammatory disease in women. Med Clin North Am 2008:92:1083-113, x.

6 Hsu WC, Lee YH, Chang DY. Tuboovarian abscess caused by Candida in a woman with an intrauterine device. Gynecol Obstet Invest 2007:64:14-16.

7 Luedders DW, Chalvatzas N, Banz C. Tubo-ovarian abscess in woman with an intrauterine device forgotten for 22 years. Gynecol Surg 2009;7:181-4. http://www.springerlink.com/content/ a81644888650552q/.

8 Amy JJ, Tripathi V. Contraception for women: an evidence based overview. BMJ 2009;339:b2895.

\section{Learning points}

- Clinicians must always consider forgotten contraceptive devices as a potential cause of acute sepsis even after exclusion in the presenting history.

- Infected devices may yield atypical organisms that are often unresponsive to initial treatment-further investigations must be sought immediately to prevent unnecessary deterioration.

- Both IUCD users as well as primary care practitioners must advocate regular device checks for as long as local guidelines dictate.

Competing interests None.

Patient consent Obtained.

This pdf has been created automatically from the final edited text and images.

Copyright 2010 BMJ Publishing Group. All rights reserved. For permission to reuse any of this content visit

http://group.bmj.com/group/rights-licensing/permissions.

BMJ Case Report Fellows may re-use this article for personal use and teaching without any further permission.

Please cite this article as follows (you will need to access the article online to obtain the date of publication).

Thrumurthy SG, Tiew S, Wood N, Bhowmick A. Candida: an unexpected cause of the acute abdomen. BMJ Case Reports 2010;10.1136/bcr.04.2010.2948, date of publication

Become a Fellow of BMJ Case Reports today and you can:

- Submit as many cases as you like

- Enjoy fast sympathetic peer review and rapid publication of accepted articles

- Access all the published articles

- Re-use any of the published material for personal use and teaching without further permission

For information on Institutional Fellowships contact consortiasales@bmjgroup.com

Visit casereports.bmj.com for more articles like this and to become a Fellow 